\title{
Prevalence of Three-rooted Primary Mandibular First Molars in Children of Davangere, Karnataka, India
}

\author{
${ }^{1}$ NB Nagaveni, ${ }^{2}$ P Poornima, ${ }^{3}$ Anila Vilsan, ${ }^{4}$ Mebin G Mathew, ${ }^{5}$ Safina Masroor
}

\begin{abstract}
Aim: To evaluate the prevalence of three-rooted primary mandibular first molars in children of Davangere, Karnataka, India.

Materials and methods: Children aged 3 to 10 years, who reported to the Department of Pedodontics and Preventive Dentistry, during the period of January to December 2014 were included in the study. Intraoral periapical radiographs of bilateral primary mandibular first molars, obtained from 77 patients, were investigated for the presence of an additional root. A total of 154 primary mandibular first molars were examined.
\end{abstract}

Results: The total occurrence of three rooted primary mandibular first molar among the study subjects was $1.3 \%$. There was noted an equal distribution among boys and girls (1:1). Both the three rooted primary first molar occurred on the right side with no bilateral occurrence noted.

Conclusion: Primary mandibular first molar can display several anatomical variations, most frequently supernumerary root located distolingually. Hence, pedodontists should be alert in the identification of additional roots and to make necessary treatment modifications.

Clinical significance: An awareness and understanding of the presence of additional roots and unusual root canal morphology are essential as it determines the successful outcome of the endodontic treatment.

Keywords: Primary first mandibular molars, Radix endomolaris, Radix paramolaris, Root anomaly, Three-rooted mandibular molars.

How to cite this article: Nagaveni NB, Poornima P, Vilsan A, Mathew MG, Masroor S. Prevalence of Three-rooted Primary Mandibular First Molars in Children of Davangere, Karnataka, India. CODS J Dent 2017;9(1):7-9.

Source of support: Nil

Conflict of interest: None

\section{INTRODUCTION}

The morphology of deciduous teeth, in comparison with their permanent counterparts, is thinner enamel and dentin, and larger pulp chamber with accentuated

${ }^{1}$ Professor, ${ }^{2}$ Professor and Head, ${ }^{3-5}$ Postgraduate Student

${ }^{1-5}$ Department of Pedodontics and Preventive Dentistry, College of Dental Sciences, Davangere, Karnataka, India,

Corresponding Author: NB Nagaveni, Professor, Department of Pedodontics and Preventive Dentistry, College of Dental Sciences, Davangere, Karnataka, India, Phone: +918971695506, email: nagavenianurag@gmail.com pulp horns. ${ }^{1,2}$ Hence, deciduous teeth often present postcarious pulpal implications that require appropriate intervention. ${ }^{3}$ Rather than premature extraction, a more conservative treatment approach, the retention of primary teeth through restorative or endodontic means has been evolved amongst dental practitioners and pediatric dental specialists. ${ }^{4}$ The main objective of pulp therapy in the primary dentition is to retain every primary tooth as a fully functional component in the dental arch to allow for proper mastication, phonation, swallowing, preservation of the space required for the eruption of permanent teeth and prevention of detrimental psychological effects due to tooth loss. ${ }^{3}$ To achieve this goal, a sound knowledge of the normal and abnormal morphology of primary teeth roots and root canal systems is required in making diagnosis and treatment decisions in young patients. ${ }^{4,5}$

Primary mandibular first molars usually have two roots and three root canals, with the formation of accessory roots being uncommon. ${ }^{6}$ The prevalence of dental anomalies is lower in the primary dentition than in permanent dentition. ${ }^{78}$ The occurrence of an extra distal root in these molars is considered a racial characteristic of certain native Indian and Mongoloid populations.,10 There have been several case reports on the occurrence of three-rooted primary mandibular first molar variants, but research activities on their prevalence in South Indian population are rare. Therefore, the purpose of this study was to evaluate the prevalence of three-rooted primary mandibular first molars in children of Davangere, Karnataka, India.

\section{MATERIALS AND METHODS}

Children aged 3 to 10 years, who reported to the Department of Pedodontics and Preventive Dentistry, from January to December 2014 were included in the study. Before the onset, the study design was reviewed and ethical clearance obtained from the institutional review board. The intraoral periapical radiographs of bilateral primary mandibular first molars taken for specific diagnostic or treatment requirements were utilized for screening and examination in this study. To reduce radiographic misinterpretation, blurred images of teeth were excluded. A total of 154 primary mandibular first molars in 77 
Table 1: Number and percentage of total occurrence of three rooted primary first molars

\begin{tabular}{|c|c|c|}
\hline \multirow[b]{2}{*}{ Additional root } & \multicolumn{2}{|c|}{ First primary molar } \\
\hline & $(n)$ & (\%) \\
\hline Yes & 2 & 1.3 \\
\hline No & 152 & 98.7 \\
\hline Total & 154 & 100 \\
\hline
\end{tabular}

patients (41 males and 36 females) possessing bilateral primary mandibular first molars were thus obtained.

The intraoral periapical radiographs were made using the standardized paralleling cone technique with the aid of a position indicator device to minimize error and to obtain images of adequate quality. Two calibrated dentists, both pediatric dentistry specialists, examined the periapical radiographs using a magnifying lens. The criteria for the presence of an extra root were based on the crossing of radiolucent lines that defined the pulp space and the periodontal ligaments in the primary mandibular first molars. Consensus between the two investigators resolved. ${ }^{11,12}$ Disagreements in the interpretation of radiographs.

The total prevalence, sex ratio, and prevalence of bilateral and unilateral and right- and left-sided threerooted primary mandibular first molars were evaluated.

\section{Statistical Analysis}

The obtained data were subjected to descriptive analysis.

\section{RESULTS}

The total occurrence of three rooted primary mandibular first molar among the study subjects was 1.3\% (2/154). There was noted an equal distribution among boys and girls (1:1). Both the three rooted primary first molar occurred on the right side with no bilateral occurrence noted. The results were tabulated in Tables 1 to 3 .

\section{DISCUSSION}

Radix endomolaris (RE), an additional third root was first mentioned in the literature by Carabelli in 1844 and is described by various other terms, such as "extra third root" or "distolingual root" or "extra distolingual root." ${ }^{13}$ Radix paramolaris (RP) is known as the additional "mesiobuccal root" and was first described by Bolk in $1915 .^{14}$

Table 3: Prevalence of three rooted primary first molars among different sides

\begin{tabular}{lll}
\hline & \multicolumn{2}{l}{ First primary } \\
Additional root & $(n)$ & $(\%)$ \\
\hline Right & $2 / 77$ & 2.6 \\
Left & 0 & 0 \\
Bilateral & 0 & 0 \\
Total & $2 / 154$ & 1.3 \\
\hline
\end{tabular}

Table 2: Prevalence of three rooted primary first molars among boys and girls

\begin{tabular}{|c|c|c|}
\hline \multirow[b]{2}{*}{ Additional root } & \multicolumn{2}{|c|}{ First primary molar } \\
\hline & $(n)$ & $(\%)$ \\
\hline Male & $1 / 82$ & 1.2 \\
\hline Female & $1 / 72$ & 1.4 \\
\hline Total & $2 / 154$ & 1.3 \\
\hline
\end{tabular}

Primary teeth with fully developed roots exhibit a less complex root canal system compared to permanent teeth, with one canal per root. However, the complexity of this system may increase over time due to the formation of secondary dentine and narrowing of the canal system and eventually the resorption process. ${ }^{15}$ Tratman et al. stated that RE is not simply a division of the distal root but rather is a true extra root (mostly distolingual) with a separate orifice and apex. ${ }^{7}$

Analyzing the root configuration in primary molars can be difficult because of the presence of physiologic or pathologic root resorption, exfoliation, and extraction. Owing to the root divergence, extraction of primary molars with sound roots is rather difficult. Therefore, fewer studies have investigated the incidence of the third root in primary molars, and the scanty literature includes majorly case reports, ${ }^{16-21}$ with very few studies on the prevalence of extra roots in first primary molars. ${ }^{12,22}$ However, the rarity of reports of anomalous root patterns in primary teeth may not reflect the real situation.

Tratman et al. reported that three-rooted mandibular first molars are rare with a frequency of $<1 \%$ in the primary dentition and common in the permanent dentition. ${ }^{7}$ In the present study in the South Indian population, a total occurrence of $1.3 \%$ was noted. A radiographic Japanese survey revealed that $5.6 \%$ of 1408 samples of mandibular first primary molars had an additional distolingual root. ${ }^{22} \mathrm{Tu}$ et al. reported that $5 \%$ of Taiwanese subjects had three-rooted mandibular primary first molars and that $80 \%$ of such teeth occurred unilaterally. ${ }^{12}$

The incidences of bilateral occurrence of threerooted primary first molars were reported to be $39.3 \%$ by Song et al..$^{22}$ and $17.67 \%$ by Tu et al..$^{12}$ in mongloid population.

An additional root has endodontic, exodontic, and periodontal implications in clinical pediatric dentistry. Apart from these it also has a role as a genetic marker and in forensic odontology. Anomalous root patterns may pose the great endodontic challenge, as incomplete pulp extirpation due to missed canal can result in treatment failure. ${ }^{3}$ The same caution should be followed in the treatment of primary mandibular molars with accessory roots as with permanent mandibular molars. Dentists should be familiar with multiple root anatomies to avoid missing canals. 
During extraction of primary molars with three roots, the clinician should make sure that the crown of the premolar is not trapped in the inter-radicular area of the primary molar as this could cause accidental removal of the developing permanent tooth bud. After the extraction, the dentist should examine the extracted anomalous primary molar to confirm that all roots have been retrieved. ${ }^{23}$

The RE may be a contributory factor in localized periodontal destruction. In a review article, it has been reported that patients with a distolingual root demonstrated a significantly greater probing depth and attachment loss at distolingual sites than at distobuccal sites. ${ }^{24}$ However, no similar finding has been reported in primary molars with additional roots.

The results of the current study, owing to the smaller sample size in only a specific region, cannot be generalized over the entire population. Hence, the author suggests that further studies with larger sample sizes need to be conducted to evaluate the relative prevalence of each population groups.

\section{CONCLUSION}

Primary mandibular first molar can display several anatomical variations, most frequently supernumerary root located distolingually. Hence to avoid untoward complications, an initial radiographic examination must be done thoroughly to help in identifying tooth root morphology and its anatomical variations, to deliver optimal care. Although the current study gives a prevalence of $1.3 \%$, further studies with larger sample sizes are needed to establish the definitive prevalence in South Indian population.

\section{Why this Study is Important to Pedodontists?}

There are limited studies on the prevalence of threerooted primary mandibular first molars in this population.

This study alerts clinicians to follow thorough initial radiographic examination so as not to miss root canals and also helps in modifying access cavity preparation.

\section{REFERENCES}

1. Finn SB. Morphology of the primary teeth. In: Finn SB et al. Clinical pedodontics. 3rd ed., WB Saunders Co., Philadelphia,1967.

2. Wheeler RC. A textbook of dental anatomy and physiology. 4th ed., WB Saunders Co., Philadelphia,1965

3. Ounsi HF, Debaybo D, Salameh Z, Chebaro A, Bassam H. Endodontic considerations in pediatric dentistry: a clinical perspective. Int Dent SA. 2009;11:40-49.

4. Cleghorn BM, Boorberg NB, Christie WH. Primary human teeth and their root canal systems. Endod Top 2012;23:6-33.
5. Fumes AC, Sousa-Neto MD, Leoni GB, Versiani MA, da Silva LA, da Silva RA et al. Root canal morphology of primary molars: a micro-computed tomography study. Eur Arch Paediatr Dent. 2014;15:317-26.

6. Tu MG, Liu JF, Dai PW, Chen SY, Hsu JT, Huang H. Prevalence of three-rooted primary mandibular first molars in Taiwan. J Formos Med Assoc 2010;109:69-74.

7. Tratman EK. Three-rooted lower molars in man and their racial distribution. Br Dent J 1938;64:264-74.

8. Menczer LF. Anomalies of the primary dentition. J Dent Child. 1955;22:57-62.

9. Curzon ME, Curzon JA. Three-rooted mandibular molars in the Keewatin Eskimo: Its relationship to the prevention and treatment of caries. J Can Dent Assoc 1972;38:152.

10. Mayhall JT. Three-rooted deciduous mandibular second molars. J Can Dent Assoc. 1981;47:319-321.

11. Walker RT, Quackenbush LE. Three-rooted lower first permanent molars in Hong Kong Chinese. Br Dent J. 1985;159:298_299.

12. Tu MG, Tsai CC, Jou MJ, Chen WL, Chang YF, Chen SY. Prevalence of three-rooted mandibular first molars among Taiwanese individuals. J Endod 2007;33:1163-1166.

13. Carabelli G. SystematischesHandbuch der Zahnheikunde. 2nd ed. Vol. 114. Vienna: Braumuller and Seidel;1844.

14. Bolk L. Bemerkungen u berWurzelvariationen am menschlichenunterenMolaren. Zeiting fur Morphologie Anthropologie 1915;17:605-610.

15. Nagaveni NB, Poornima P, Valsan A, Mathew MG. Prevalence of three rooted primary mandibular second molars in Karnataka(South India) Population. Int J Pedod Rehabil 2018; 3:33-35.

16. Falk WV, Bowers DF. Bilateral three rooted mandibular first primary molars: Report of case. J Dent Child. 1983;50:136-137.

17. Nagaveni NB, Chandani GR, Kothari S, Poornima P. Radix entomolaris in children - A challenge to pedodontist: A report of case series with literature review. Int J Contemp Dent Med Rev.2015;2015.

18. Nagaveni NB, Bajaj M, Shruthi AS, Poornima P. Radix paramolaris (supernumerary third root) in primary mandibular second molar: Report of two cases. Niger J Exp Clin Biosci 2014;2:134-137.

19. Gupta S, Nagaveni NB, Chandranee NJ. Three-rooted mandibular first primary molar: Report of three cases. Contemp Clinic Dent. 2012;3:S134-S136.

20. Ramamurthy N, Srinivasan I. Bilateral three-rooted primary lower molars. Indian J Dent Res 2012;23:700.

21. Nagaveni NB, Umashankar KV, Radhika NB, Satisha TS. Third root (Radix Entomolaris) in permanent mandibular first molars in pediatric patients - An Endodontic challenge. Journal of Oral Health and Community Dentistry 2011;5:4951.

22. Song JS, Choi HJ, Jung IY, Jung HS, Kim SO. The prevalence and morphologic classification of distolingual roots in the mandibular molars in a Korean population. J Endod 2010;36:653-657.

23. Nagaveni NB, Umashankara KV. Radix entomolaris and paramolaris in children:A review of the literature. J Indian SocPedodPrev Dent 2012;30:94-102.

24. Nagaveni NB, Umashankara KV. Radix entomolaris in permanent mandibular first molar: case report and literature review. Gen Dent 2009;57:e25-29. 